\title{
Deslocamento da linha de costa versus mobilidade praial
}

\section{Coastline displacement versus beach mobility}

\section{Dieter Muehe $^{\text {ace }}$ Leonardo Klumb-Oliveira $^{\text {bdf }}$}

\author{
${ }^{a}$ Universidade Federal do Rio de Janeiro, brograma de Pós-Graduação em Geografia, Laboratôrio de Geografia Marinha, \\ Universidade Federal do Rio de Janeiro, ' Professor Visitante Sênior-CAPES do_Programa de Pós-Graduação em Geografia, \\ Universidade Federal do Espírito Santo, ${ }^{\mathrm{d}}$ Bolsista doutorado CAPES \\ edieter.muehe@gmail.com, ${ }^{\mathrm{f} l e o k l u m b @ g m a i l . c o m ~}$
}

\begin{abstract}
Resumo
Nas estimativas da variação da linha de costa ao longo dos anos, assim como para análise da sua tendência erosiva ou progradacional atual são frequentemente utilizadas fotografias aéreas e imagens de satélite, nas quais é comum o uso da linha de contato entre a areia seca e molhada da praia como indicador do nível da preamar média. No entanto, dependendo do referencial utilizado, o resultado pode levar à interpretações equivocadas, destacadamente no que concerne à perspectiva da mobilidade da praia ou apenas a sua variabilidade morfodinâmica.
\end{abstract}

Palavras chave: Linha de costa; mobilidade; mapeamento

\begin{abstract}
The mapping of the dry and moist limit of the beach on aerial photos or satellite images as a proxy for the shoreline position in order to establish the mobility of the coast is a widely used technique. As the morphological variability of some beaches can be in the order of decameters without representing a trend of the coastline considering as such the contact of the backshore or beach berm with the back beach (foredune toe, erosion scarp or bluff), the result my, in some cases, not represent the real trend of the coast line, but only the beach morphodynamic variability.
\end{abstract}

Key words: Shoreline mobility; beach morphodynamics; shoreline definition

\section{Introdução}

A linha de costa oceânica é definida pela interseção entre o nível do mar e a terra firme. Considerando que essa posição depende da maré é preciso definir que maré deve ser considerada, ou seja, qual das alturas entre as marés máximas e mínimas de sizígia. Dependendo dos objetivos, várias opções podem ser escolhidas cujos resultados poderão ser mais ou menos significativos, em termos de localização, dependendo da amplitude da maré e declividade da orla costeira.

Num caso mais extremo, como o da determinação dos terrenos de marinha, onde o nível do mar a ser considerado é a preamar média de 1836 (Decreto-Lei $n^{0} 9760$ de 5 de setembro de 1946), não só é extremamente difícil reproduzir este nível quanto mais difícil, senão impossível, é reconstituir a interseção deste nível com a linha de costa já que, no caso das orlas constituídas por praias a mesma pode ter recuado, ou avançado, numa ordem de grandeza até superior aos 33m previstos para esta faixa (Angulo 1993, Roso 2008). Em praias de estágio morfodinâmico intermediário a própria variabilidade morfodinâmica da praia pode ultrapassar este valor.

Não obstante, por ser a praia uma das feições mais recorrentes da orla costeira, é também a mais considerada nos estudos de variabilidade morfodinâmica e da mobilidade da linha de costa no sentido de identificar tendências de erosão, estabilidade ou progradação. Não são infrequentes os erros cometidos nesse tipo de monitoramento ao não distinguir tendências de situações de curto prazo, o que exige a manutenção dos monitoramentos por espaços de tempo adequados. O emprego de imagens de satélites ou fotos aéreas de apenas duas situações leva facilmente a erros de interpretação.

Quanto à identificação de taxas de erosão costeira os resultados obtidos no monitoramento de uma praia podem não corresponder ao que ocorre de fato em termos de recuo da retroterra, isto é no contato da póspraia com a base da duna frontal ou com a escarpa do final da praia. Um belo exemplo nesse sentido foi mostrado no litoral do Rio Grande do Sul onde o monitoramento da praia com passagens sucessivas de um DGPS resultou inicialmente na interpretação de erosão generalizada da orla (Toldo et al. 1999) para, após aumento do número de passagens, se identificar uma ritmicidade nos eventos de acumulação e progradação limitada à própria praia sem que tenha implicado em erosão da retroterra (Esteves 2006). Esta, quando presente, ocorre em hotspots associado a convergência de ortogonais das ondas (Speranski \& Calliari 2006). Já em locais com déficit sedimentar, e consequentemente rápida retrogradação da orla, o 
monitoramento da praia permite uma avaliação adequada da tendência retrogradacional da orla como mostram os trabalhos de Farias \& Maia (2010) e Marino \& Freire (2013).

No Rio de Janeiro, as longas praias entre a Marambaia e o Cabo Frio francamente expostas a eventos extremos e sem aporte de sedimentos continentais, tem apresentado uma resiliência surpreendente no sentido da completa recuperação do estoque de sedimentos sem mudança de posição média de interseção da face da praia com o nível médio do mar, mesmo com o recuo de mais de um decâmetro da escarpa da retroterra por ocasião da tempestade de maio de 2001 (Muehe 2011).

Em vista do exposto o monitoramento da praia pode não necessariamente expressar o comportamento da orla no que tange à identificação de tendências que podem representar um risco para as áreas identificadas. Em outras palavras a escolha da praia e ainda mais especificamente a escolha da linha de referência para a representação da interseção do nível do mar com a praia, como referência à identificação de processos erosivos, pode nem sempre ser o indicador mais adequado. Sendo esse o aspecto que passará a ser abordado no presente trabalho.

\section{A escolha da linha de controle - face da praia, linha de preamar ou escarpa da retroterra?}

O método mais preciso para indicar a variabilidade de uma praia é o monitoramento por meio de nivelamento topográfico, que permite a determinação de um referencial fixo de interseção do nível do mar, seja qual for o nível escolhido, a partir de uma previsão maregráfica (Muehe et al. 2003). Como o perfil pode ser estendido para a retaguarda da praia, como dunas frontais ou a escarpa da pós-praia, esse tipo de monitoramento também pode incluir esta parte da orla. Sua desvantagem, além de não ser possível aplicar na reconstituição de linhas de costas pretéritas, é sua representatividade apenas pontual o que pode ser parcialmente compensado pela realização de vários perfis ao longo da praia e se possível complementado por fotografias aéreas ou imagens de satélite. Uma ferramenta de grande ajuda é o sistema de análise computacional Digital Shoreline Analysis System, uma rotina desenvolvida para o Programa ArcGis disponível gratuitamente no site http://woodshole.er.usgs.gov/ project-pages/dsas/ do United States Geological Survey. Por meio deste sistema é possível traçar um conjunto de perfis transversais à linha de costa, tendo como base fotos aéreas ou imagens de satélite, e realizar a análise do comportamento da linha de costa, qualquer que seja o referencial escolhido, desde que seja identificável nas imagens usadas. Isto torna a escolha do indicador o ponto focal da questão.

Um dos indicadores mais usados pela sua facilidade de identificação em imagens aéreas é a mudança de cor entre a superfície úmida e seca da praia (Leatherman 2003), resultante da posição do alcance das ondas na preamar antecedente à tomada da imagem. Segundo esse autor essa medida é uma substituição da "linha de deixa” - resíduos deixados na praia pelas ondas usado pelos topógrafos como proxy da linha de preamar. Essa identificação nem sempre é muita clara, podendo levar a erros significativos de posicionamento como exemplificado na figura 1 além de ser mais indicado para regimes de micromaré semidiurna (Crowell 1991) podendo-se acrescentar uma restrição adicional qual seja a de praias intermediárias que podem apresentar variações, na largura da berma, da ordem de meia centena de metros (figura 2). A depender do momento em que a imagem é feita, a variação da largura da praia, entre duas imagens distintas, pode ser decorrente apenas do estado morfodinâmico no momento da tomada da imagem, e não resultado de um processo erosivo ou progradacional continuado.

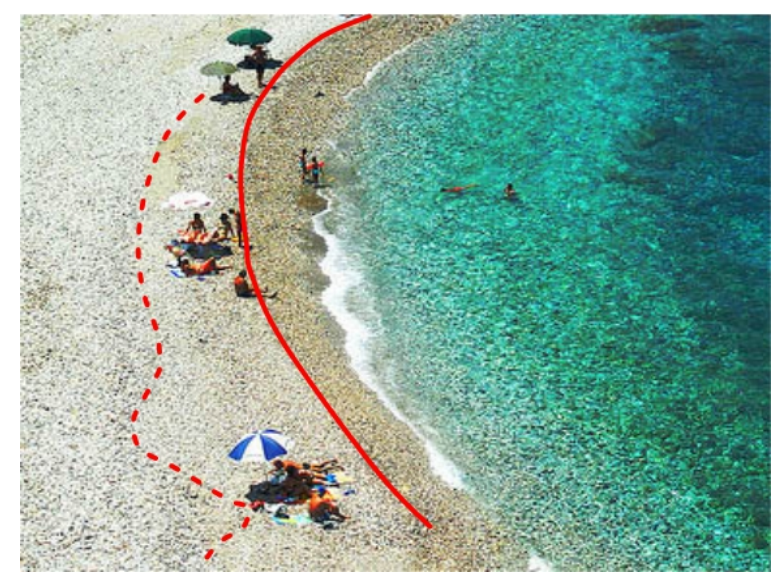

Figura 1: Linha de contato entre a praia úmida e seca como proxy para o localização da linha de costa. Observa-se uma segunda faixa, menos úmida, de contraste menos acentuado. Dependendo qual das linhas for escolhida, a diferença é métrica.

Um segundo indicador, mais significativo para a avaliação do deslocamento da linha de costa no sentido de indicar um risco às áreas urbanizadas à retaguarda, é o contato da berma da praia com a retroterra. Este pode ser representado por uma escarpa ou pequena falésia erosiva entre a praia e o cordão litorâneo ou terraço costeiro, ou ainda a base da duna frontal. Esta última, segundo Carter et al. (1990), pode se apresentar em três estados distintos (pré-erosivo, erosivo e pós-erosivo ou pós tempestade), quando a escarpa íngreme da face da duna é suavizada por uma rampa formando um novo perfil de repouso. De acordo com Baptista et al. (2011), a escarpa entre o terceiro e quarto estágio é bem visível em imagens de satélite, mas tende a ser obliterado ao longo do tempo por sucessivos escorregamentos o que pode dificultar a identificação. O recobrimento vegetal também pode gerar erros de interpretação. Assim sendo, o melhor modo de mapear este contato, é percorrer este limite com um DGPS, à pé ou empregando um veículo compatível com ambiente arenoso (4X4) como descrito por Baptista et al. (2011). No caso do emprego de imagens aéreas é preciso verificar o nível de contraste entre a praia e a base da duna para avaliar a adequação do emprego da 
imagem. Finalmente na ausência de qualquer mudança brusca de topografia entre a praia e a retroterra resta usar o aparecimento de vegetação permanente como indicador da linha de costa.

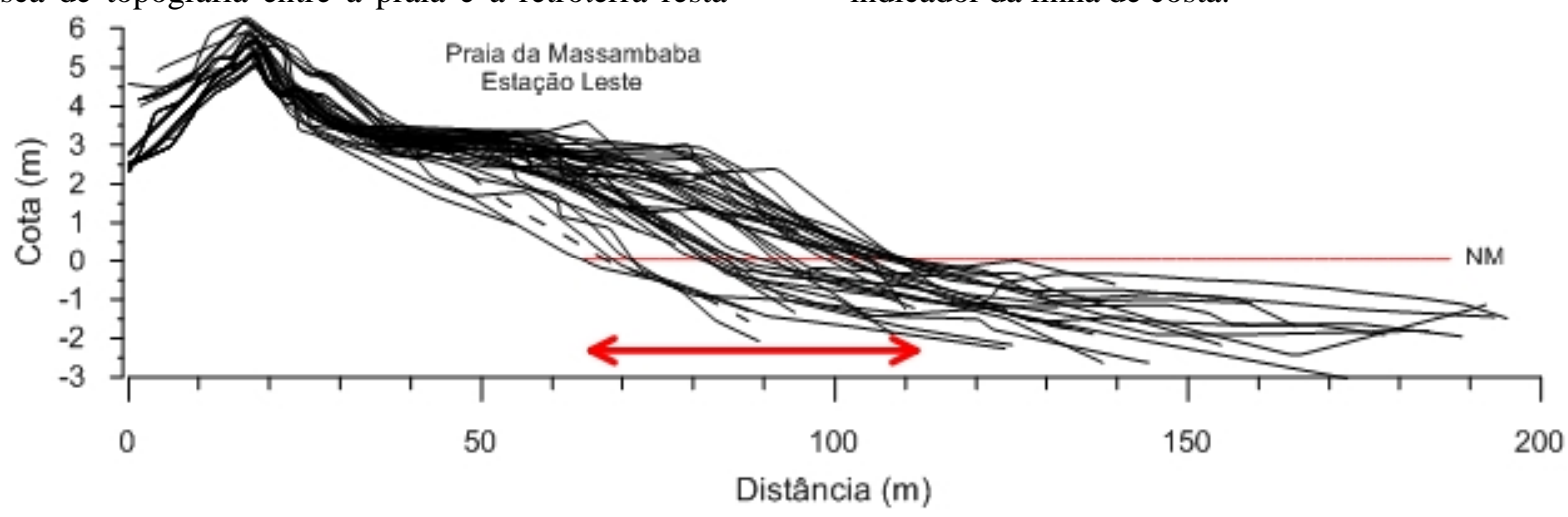

Figura 2: Variação da largura de uma praia de estágio morfodinâmico intermediário. Praia da Massambaba, a oeste de Arraial do Cabo, Rio de Janeiro.

\section{Um estudo de caso}

Para testar a diagnosticidade dos dois critérios indicadores da mobilidade da linha de costa foi escolhida uma praia no litoral a norte do Cabo Frio e que após um período de estabilidade passou a apresentar uma tendência erosiva, acentuada após uma tempestade excepcionalmente intensa em 2010, com ondas de 4 a $5 \mathrm{~m}$ em mar aberto, período de $11 \mathrm{~s}$ e duração de três dias, vindo de sul-sudeste. O recuo da base da duna frontal foi resultado direto da ação da tempestade já a configuração da linha de praia pode não mais refletir este efeito devido à mobilização sedimentar subsequente, o que não importa para os objetivos do presente trabalho que é o de demonstrar o comportamento diferenciado dos indicadores analisados.

Entre as relativamente poucas imagens disponíveis foram escolhidas duas que exemplificassem de forma contundente o comportamento nem sempre sincrônico entre a praia e a escarpa da pós-praia, sendo uma antes e outra após a referida tempestade. Mais especificamente foi escolhida uma ortofoto do IBGE de 2008 e outra, uma imagem Ikonos de 2011. Foram traçadas as linhas da face da praia no contato da areia úmida com a seca e a da base da duna frontal. Para a representação da variabilidade das duas linhas ao longo do arco praial foi empregado o programa DSAS, mencionado acima, sendo os resultados apresentados em forma gráfica através do programa Grapher da Golden Software Inc.

\section{Resultado}

A figura 3 mostra o resultado da comparação entre a linha de praia e entre a escarpa da duna frontal. É preciso ressaltar que, na metodologia empregada, erros devido à resolução da imagem, georeferenciamento e localização da linha de delimitação, são na faixa de 5 a $10 \mathrm{~m}$ de modo que as variações encontradas devem ser vistas mais como uma indicação de tendência do que em termos de valores absolutos.

O que se observa é que, enquanto ocorreu um recuo generalizado da base da duna frontal ao longo de todo o arco praial, esta tendência erosiva se inverteu na praia que de erosiva, no seu segmento sul, passou a progradacional em direção ao norte indicando uma rotação do arco praial com acréscimo de sedimentos da antepraia (figura 3).

\section{Arco de praia do Peró}
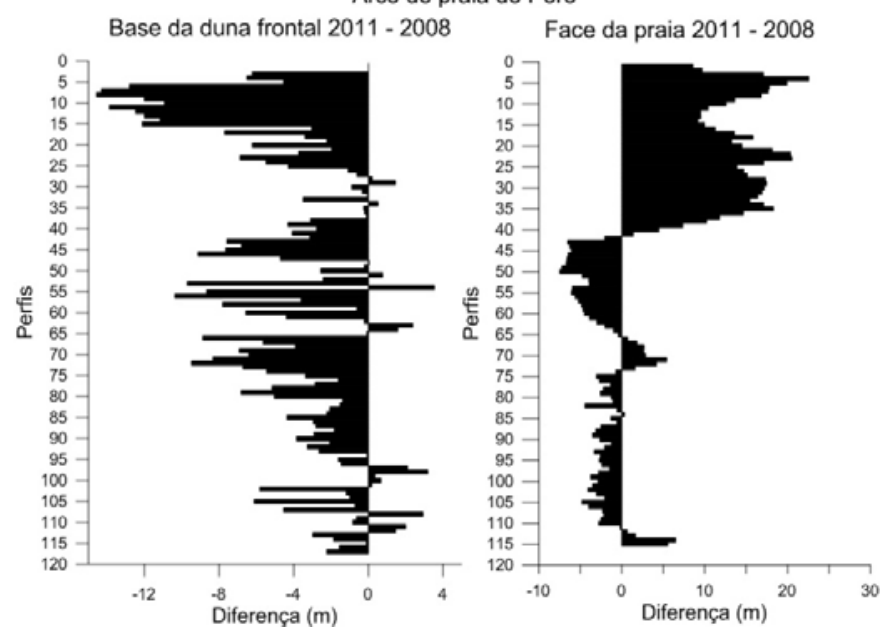

Figura 3: Comparação entre o comportamento da base do campo de dunas frontais e a face da praia. Enquanto no primeiro caso há erosão generalizada em decorrência da ressaca de 2010, a praia passa de erosão na metade sul para progradação na metade norte. 


\section{Conclusão}

A utilização do contato seco e úmido da face da praia em imagens aéreas para fins de reconstituir a evolução da linha de costa deve ser interpretada com cuidado, principalmente quando se empregam apenas duas imagens como indicação de tendência. Isto porque a variabilidade morfodinâmica da praia pode implicar em variação de sua largura na ordem de dezenas de metros, principalmente no caso de praias intermediárias, sem que isto represente uma tendência. Isto é especialmente importante quando se quer inferir a taxa de recuo do limite da pós-praia (falésia, base da duna frontal, contato da praia com a retroterra), pois é esta taxa a que vai permitir avaliar o grau de risco para áreas urbanizadas próximas, sendo por isso o limite mais adequado de monitoramento. Por outro lado, considerando a maior facilidade de identificação do limite da face ativa da praia e a frequentemente maior dificuldade de mapear o limite da pós-praia, a primeira alternativa continuará a ser uma técnica largamente empregada. Uma solução para reduzir os erros potenciais de interpretação é ampliar o número de imagens e ainda levar em conta o tipo morfodinâmico da praia em estudo. A comparação de imagens históricas no Google Earth pode servir para uma confirmação da tendência encontrada. Já para o monitoramento, em campo, da evolução da orla, o ideal será uma combinação de perfis topográficos com levantamento do limite da pós-praia por meio de caminhamento com DGPS.

\section{Agradecimentos}

O presente trabalho faz parte do Projeto vulnerabilidade e riscos potenciais associados às mudanças climáticas: litoral leste e sul-oriental do Estado do Rio de Janeiro. (CNPq grant Proc. 304165/2009-3). Projeto associado ao Programa de Geologia e Geofísica Marinha (PGGM) e à Rede Clima.

\section{Referências}

Angulo R.J. 1993. Variações na configuração da linha de costa do Paraná nas últimas quatro décadas. Boletim Paranaense de Geociências, Curitiba, 41:52-72.

Baptista P., Cunha T., Bernardes C., Gama C., Ferreira Ó., Dias A. 2011. A precise and eficient methodology to analyse the shoreline displacement rate. Journal of Costal Research, 27(2):223-232.

Carter R.W.G., Hesp P.A., Nordstrom K.F. 1990. Erosional landforms in coastal dunes. In: Nordstrom K.F., Psuty N.P., Carter R.W.G. (eds.), Coastal Dunes: Form and Process. New York: Wiley: 217-250.

Crowell M., Leatherman S.P., Buckley M.K. 1991. Historical shoreline change: error analysis and mapping accuracy. Journal of Coastal Research, 7(3):839-852.

Esteves L.S. 2006. Variabilidade espaço-temporal. In: Muehe D. (org.). Erosão e Progradação do Litoral Brasileiro. Brasília, Ministério do Meio-Ambiente (MMA), Governo Federal: 460467.

Farias E.G.G., Maia L.P. 2010. Uso de técnicas de geoprocessamento para a análise da evolução da linha de costa em ambientes litorâneos do Estado do Ceará, Brasil. Revista da Gestão Costeira Integrada, 10(4):521-544
Leatherman S. 2003. Shoreline change mapping and management along the U.S. East Coast. Journal of Coastal Research, SI(38):53.

Marino M.T.R.D., Freire G.S.S. 2013. Análise da evolução da linha de costa entre as praias do Futuro e Porto das Dunas, região metropolitana de Fortaleza (RMF), Ceará State, Brazil, Revista da Gestão Costeira Integrada, 13(1):113-129.

Muehe D. 2011. Erosão costeira: Tendência ou eventos extremos? O litoral entre Rio de Janeiro e Cabo Frio, Brasil. Revista da Gestão Costeira Integrada, 11(3):315-325.

Muehe D., Roso R.H., Savi D.C. 2003. Avaliação de método expedito de determinação do nível do mar como datum vertical para amarração de perfis de praia. Revista Brasileira de Geomorfologia, 4(1):53-57.

Roso R.H. 2008. Terrenos de marinha. Monografia apresentada à Escola de Guerra Naval. Rio de Janeiro. 54p.

Speranski N.S., Calliari L.J. 2006. Padrões de refração de ondas para a costa do Rio Grande do Sul e sua relação com a erosão costeira. In: Muehe D. (org.). Erosão e Progradação do Litoral Brasileiro. Brasília, Ministério do Meio-Ambiente (MMA), Governo Federal:446-454.

Toldo Jr. E.E., Almeida L.E.S., Barros C., Martins L.R. 1999. Retreat of the Rio Grande do Sul coastal zone, Brazil. In: Martins L.R., Santana C.I. (org.). Non Living Resources of the Southern Brazilian Coastal Zone and Continental Margin, Porto Alegre, Brazil: Editora da UFRGS: 62-68

Recebido 27 de março de 2014 Aceito 08 de agosto de 2014 